Brit. J. vener. Dis. (1955), 31, 143.

\title{
STUDIES ON THE TREPONEMAL IMMOBILIZATION TEST
}

\section{USE OF THE TPI AS A VERIFICATION TEST IN SUSPECTED LATENT SYPHILIS * $\dagger$}

BY

\author{
A. E. WILKINSON
}

Venereal Diseases Reference Laboratory (Medical Research Council) and Whitechapel Clinic Laboratory, London Hospital

\author{
AND \\ P. J. L. SEQUEIRA \\ Royal Free Hospital, London
}

In latent syphilis the diagnosis frequently rests purely on serological grounds, there being no clinical or epidemiological evidence to corroborate the serological findings. In these circumstances, a great responsibility rests upon the serological tests employed, and an enormous volume of research has been directed to raising the sensitivity of these tests to as high a level as possible without compromising their specificity. The application of serum testing on a mass scale to presumably healthy populations with a view to discovering unsuspected cases of syphilis has emphasized the paramount importance of specificity, and it has been suggested (Kahn and McDermott, 1953) that too much stress has been laid upon the sensitivity of tests at the expense of their specificity. This view is borne out by the results given by routine tests performed before demobilization which showed 75,000 American servicemen to be sero-positive, who were known to be sero-negative on entry into the services and who had no history of venereal infection. Sample surveys showed that of those who were again found to be sero-positive on re-testing, more than half had probable biological false positive reactions (Moore and Mohr, 1952a).

Although this American experience may have focused attention on the problem, dissatisfaction with serum tests for syphilis (STS) using lipoidal antigens has long been felt, as shown by the numerous verification tests which have been devised in the past. In general, these have been based on alterations in the physical conditions of the tests, but have used the same lipoidal antigens, and none has proved generally satisfactory. Tests using lipoidal antigens are usually said to be non-specific

* Received for publication June 6, 1955 .
+Based on an address given to the M.S.S.V.D. on February 25, 1955. in the sense that they do not represent a reaction between an antibody and the causative organism of the disease. However, there is some evidence that the virulent Nichols strain of $T$. pallidum may contain a component responsible for reagin production (Hardy and Nell, 1955), and similar findings have been reported for the avirulent Reiter treponeme by the Italian school of serologists (D'Alessandro, Oddo, and Dardanoni, 1950). Attempts to use virulent $T$. pallidum as an antigen, and hence realize a specific test, have been hampered by continued failure to grow the organism in vitro. Tani and Asano (1951) described an agglutination test using killed treponemes of the Nichols strain extracted from the testes of infected rabbits. This work attracted little attention at the time and it was not until Nelson and Mayer (1949) developed the Treponemal Immobilization Test (TPI) that interest in techniques using virulent treponemes was re-awakened. The TPI test shows the presence of an antibody in syphilitic serum clearly acting on the parasite and requiring complement for its action. It is highly specific for treponemes of the syphilis-yaws-bejel group, and from its inception it was clear that it might find a useful application in patients with suspected latent syphilis to differentiate true syphilitic reactions in tests using lipoidal antigens from " biological false positive" or non-specific reactions (NSR).

Any verification test designed for use in this connexion must fulfil certain criteria :

(a) It must be specific for treponemal infection and reproducible. These aspects of the TPI have been reviewed by Zellmann (1954) and by Sequeira and Wilkinson (1955).

(b) Its sensitivity should be sufficiently high to give positive reactions in all cases of latent syphilis. 
(c) Ideally, it should be unaffected by treatment so that it can give a retrospective confirmation of the original diagnosis where treatment has been given.

(d) It should give a clear-cut " yes or no" answer with the minimum of doubtful or indeterminate results.

Although patients with latent syphilis have been included in many of the surveys of the results given by the TPI at various stages of syphilis, in some of the literature it is not clear whether the diagnosis of "latent syphilis" rested solely on serological findings or whether there was other evidence to substantiate it. The incidence of negative TPI results also varies widely in different reports. The principal aim of the present investigation was to establish the performance of the TPI in patients with proved latent syphilis, and to see how it fulfilled the criteria of a verification test outlined above. The test has also been applied to patients with "latent syphilis" attending two venereal disease clinics and to the examination of a large number of " problem sera".

\section{Technique and Clinical Material}

The Treponemal Immobilization Test technique used closely followed that originally described by Nelson and Mayer (1949) with the minor modifications noted in a previous paper (Wilkinson, 1954b). For convenience of description, the sera tested have been divided into the following groups :

(a) Sera from patients with latent syphilis where the diagnosis rested on other evidence besides the serological findings.

(b) Patients with latent syphilis attending the Whitechapel Clinic, London Hospital, and the Venereal Diseases Department of the Royal Free Hospital.

(c) "Problem" sera sent to the Venereal Diseases Reference Laboratory (Medical Research Council) from patients whose STS had been found positive on routine testing in other laboratories.

(d) Sera from patients with leprosy, lupus erythematosus, or haemolytic anaemia, conditions in which nonspecific STS reactions are thought to be frequent.

On receipt in the laboratory, sera were separated and divided into two portions. One was stored at $-20^{\circ} \mathrm{C}$. until the TPI test could be carried out, and four STS were performed on the other,

$(1,2)$ Wassermann Reactions with crude heart extract and cardiolipin antigens, using the Whitechapel technique (Price, 1950).

(3) Standard Kahn Test.

(4) Price's Precipitation Reaction (PPR) (Price, 1948).

In the case of the Royal Free Hospital patients, the cardiolipin WR was not used, but the STS and TPI techniques used were the same as in the V.D. Reference Laboratory.

In all cases where the TPI result was at variance with the STS or with the clinical findings, the TPI was repeated on the same specimen of serum, and whenever possible a second specimen was obtained from the patient concerned. Doubtful TPI tests were repeated at least twice on the same specimen before being reported as such.

\section{Evaluation of the TPI Test in Patients with Confirmed Latent Syphilis}

The patients in this group showed no clinical signs of syphilis, but the diagnosis of latent syphilis was supported by other evidence than the serological findings. Four types of patients were accepted for inclusion in this study:

(a) Mothers who had given birth to congenitally syphilitic children.

(b) Patients who gave a clear history of lesions of early syphilis for which no treatment or only very inadequate treatment had been given at the time.

(c) Patients whose consorts were also sero-positive or who showed evidence of late syphilis.

(d) Patients with asymptomatic neurosyphilis. These may not necessarily be representative of latent syphilis without central nervous system involvement, but they were included because the diagnosis rests on good grounds and the disease is clinically latent.

In many instances patients qualified for inclusion under more than one of the categories listed above.

Sera from both treated and untreated patients were examined; a comparison of the STS and TPI results is given in Table $I$. In this and subsequent Tables "STS + " means that all four STS were positive, "STS 0 " that all were negative, and "STS \pm " that some were positive and others negative.

TABLE I

RESULTS OF TPI TESTS ON 136 PATIENTS IN WHOM THE DIAGNOSIS OF LATENT SYPHILIS RESTED ON OTHER EVIDENCE THAN STS FINDINGS

\begin{tabular}{|c|c|c|c|c|c|c|c|c|}
\hline \multirow{2}{*}{ Category } & \multirow{2}{*}{$\begin{array}{l}\text { Treat- } \\
\text { ment }\end{array}$} & \multirow{2}{*}{$\begin{array}{l}\text { No. of } \\
\text { Patients }\end{array}$} & \multicolumn{3}{|c|}{ STS } & \multicolumn{3}{|c|}{ TPI } \\
\hline & & & + & \pm & 0 & + & \pm & 0 \\
\hline $\begin{array}{l}\text { Mothers of congeni- } \\
\text { tally syphilitic child- } \\
\text { ren }\end{array}$ & $\begin{array}{l}\text { Untreated } \\
\text { Treated }\end{array}$ & $\begin{array}{l}14 \\
26\end{array}$ & $\begin{array}{r}7 \\
14\end{array}$ & $\begin{array}{l}2 \\
3\end{array}$ & $\begin{array}{l}5 \\
9\end{array}$ & $\begin{array}{l}13 \\
25\end{array}$ & 1 & $\overline{1}$ \\
\hline $\begin{array}{c}\text { History of early } \\
\text { syphilis }\end{array}$ & $\begin{array}{l}\text { Untreated } \\
\text { Treated }\end{array}$ & $\begin{array}{l}6 \\
2\end{array}$ & $\begin{array}{l}5 \\
2\end{array}$ & 二 & 1 & $\begin{array}{l}6 \\
2\end{array}$ & $\overline{-}$ & 二 \\
\hline $\begin{array}{l}\text { Consorts sero-positive } \\
\text { or other evidence of } \\
\text { syphilis }\end{array}$ & $\begin{array}{l}\text { Untreated } \\
\text { Treated }\end{array}$ & $\begin{array}{l}31 \\
35\end{array}$ & $\begin{array}{l}20 \\
18\end{array}$ & $\begin{array}{l}8 \\
8\end{array}$ & $\begin{array}{l}3 \\
9\end{array}$ & 29 & $\frac{2}{2}$ & 二 \\
\hline $\begin{array}{l}\text { Asymptomatic neuro- } \\
\text { syphilis }\end{array}$ & $\begin{array}{l}\text { Untreated } \\
\text { Treated }\end{array}$ & $\begin{array}{r}6 \\
16\end{array}$ & $\begin{array}{r}4 \\
10\end{array}$ & 2 & $\overline{3}$ & $\begin{array}{r}6 \\
16\end{array}$ & - & 二 \\
\hline
\end{tabular}

Sera from 136 patients were examined, in 132 of whom the TPI was positive. Three patients, all untreated, gave a doubtful TPI result. One was a woman whose husband had latent syphilis, and her TPI result was confirmed on two subsequent specimens of serum. The second patient had a history suggestive of secondary syphilis 26 years previously and had the scar of a penile sore; his 
wife was also sero-positive. The third patient had given birth to a congenitally syphilitic child. The diagnosis of latent syphilis seems to rest on good grounds in the last two cases and to be highly probable in the first.

Only one patient in the series gave a negative TPI test; the clinical history was as follows :*

A female, aged 32, was found to be sero-positive in 1942 after the birth of a child which died of "? diphtheria" at the age of 1 month. She was treated with four courses each of $0.45 \mathrm{~g}$. N.A.B. and $0.2 \mathrm{~g}$. Bi weekly for 10 weeks and became sero-negative. In June, 1945, she was delivered of a male child which developed snuffles and a rash when 1 month old. It was found to be sero-positive, and was treated by oral stovarsol and later by penicillin. In 1954 the child's STS were negative and the spinal fluid normal ; the only abnormal clinical findings were unequal pupils which did not react to light. On March 11, 1955, the child's STS were negative, but the TPI test was positive.

A month after delivery the mother's serum reactions were found to be positive again and she was re-treated with two further courses of N.A.B. and bismuth. In December, 1946, she was delivered of a healthy boy who has remained sero-negative over 7 years of observation. STS and TPI tests were carried out on the mother on November 19, 1954, and on March 11, 1955, and were negative on both dates.

In some of the published work on the results given by the TPI in latent syphilis it is not clear whether the diagnosis rested on serological grounds alone or whether it was supported by other evidence. However, Miller, Slatkin, Brodey, Wechsler, and Hill (1954) found the TPI positive in fourteen problem sera where there was other evidence of syphilis besides the STS. Zellmann (1954) found that ten women who had given birth to congenitally syphilitic children were all TPI-positive, and that 64 out of 66 patients with treated asymptomatic neurosyphilis were TPI-positive, one being doubtful and one negative. These last two patients were early cases of less than 2 years' standing. Nelson, Zheutlin, Diesendruck, and Austin (1950) found that fourteen patients with asymptomatic neurosyphilis were all TPI-positive, while Edmundson, Olansky, Wood, and Kamp (1955) reported 44 cases of this condition ( 23 of whom had been treated) who gave positive or doubtful reactions with the TPI test.

Although the present series is small, the results show that a negative TPI result was found in less than 1 per cent. of the patients with confirmed latent syphilis and it should be noted that this one patient had been treated; judging from the history, this treatment was probably given early in latency.

\footnotetext{
*I am indebted to Dr. A. E. Tinkler of the Royal Cornwal Infirmary, Truro, for supplying these clinical details.
}

Since doubtful TPI tests were found among the untreated patients, it is possible that negative TPI reactions may occur in untreated latent syphilis, but the data available at present suggest that this must be a very rare occurrence.

As far as can be judged by qualitative tests, previous treatment seems to have little effect on the TPI. Zellmann (1954) has suggested that, on analogy with the behaviour of reagin, immobilizing antibody may disappear from patients treated early in latency, but the difficulty of dating the infection makes this possibility hard to evaluate.

When a positive TPI test is obtained in patients in whom the only suggestion of latent syphilis comes from the finding of positive STS, it is felt that the demonstration of immobilizing antibody confirms past treponemal infection although it does not necessarily imply present activity of the disease process. A negative TPI test, confirmed by repetition on a second specimen of serum to exclude technical error and the possibility of a developing early syphilis, suggests very strongly that the positive STS are non-specific in nature, particularly when the patient has not received any penicillin therapy for other conditions in the past. The interpretation of a negative TPI test in patients treated for presumed latent syphilis is less certain. While it may mean that the original diagnosis was founded in error on non-specific STS reactions, there is as yet no detailed information from serial TPI tests on large numbers of individual patients of the frequency of TPI-reversal in latency. In default of this, the interpretation of negative results must, of necessity, be cautious.

\section{Results of TPI Tests on Patients with Suspected Latent Syphilis attending a Venereal Disease Clinic}

TPI tests have been carried out as an adjunct to the routine STS performed on new patients with suspected latent syphilis attending the Whitechapel Clinic at the London Hospital since July, 1952, and the Venereal Diseases Department of the Royal Free Hospital since January, 1953, and also on patients treated for latent syphilis in the past as they attended again for observation. The present review covers those patients tested up to the end of 1954 and includes those previously reported by Wilkinson (1954b). The comparative results given by the two types of test are shown in Table II (overleaf).

The untreated group of 200 patients included 23 (seventeen females and six males) who gave positive reactions with one or more of the STS, but whose TPI tests were negative, suggesting that the STS reactions were non-specific. STS had originally 
TABLE II

RESULTS OF PARALLEL STS AND TPI TESTS ON PATIENTS WITH SUSPECTED LATENT SYPHILIS ATTENDING V.D. CLINICS

\begin{tabular}{|c|c|c|c|c|c|c|}
\hline \multicolumn{2}{|l|}{ Treatment } & \multirow{3}{*}{$\begin{array}{c}\begin{array}{c}\text { No. of } \\
\text { Patients }\end{array} \\
200\end{array}$} & \multirow{3}{*}{$\begin{array}{l}\text { STS } \\
+ \\
+ \\
+\frac{1}{0}\end{array}$} & \multicolumn{3}{|c|}{ TPI } \\
\hline & & & & + & \pm & $\mathbf{0}$ \\
\hline Untreated . . & . & & & $\begin{array}{r}135 \\
29 \\
4\end{array}$ & 二 & $\begin{array}{r}5 \\
18 \\
9\end{array}$ \\
\hline Treated & . & 248 & $\begin{array}{l}+ \\
+ \\
0\end{array}$ & $\begin{array}{r}130 \\
46 \\
52\end{array}$ & $\frac{2}{-}$ & $\begin{array}{r}10 \\
1 \\
7\end{array}$ \\
\hline
\end{tabular}

been performed because of pregnancy (eight cases), blood donation (two cases), emigration (three cases), gonorrhoea or urethritis (three cases), venereophobia (two cases), and one case each of bronchitis, thyrotoxicosis, retinal oedema ? collagen disease, and pyrexia of uncertain origin. One patient was referred by a private doctor and no details are available. Both STS and TPI were negative in nine patients; these had given positive STS on previous specimens and probably represent transient non-specific reactions of unknown causation, or technical false positive reactions due to errors in the performance of the STS.

Altogether 248 patients had been treated for latent syphilis in the past, and of these eleven (ten females and one male) gave positive reactions with one or more of the STS while the TPI was negative, suggesting that the STS reactions might be nonspecific. Seven had been found sero-positive during pregnancy and two were subsequently found to have lupus erythematosus, L.E. cells having been demonstrated. One had been found sero-positive and treated 13 years previously, another had been treated 2 years previously because of positive STS found as a blood donor; she remains sero-positive. The remaining female patient was aged 72 and was found to be sero-positive during investigation of pain in the back, attributed to osteo-arthritis. The only male patient had an abrasion of the leg in 1944, which failed to heal, and on investigation his STS were found to be positive. Despite very intensive treatment his STS have increased in titre ; he also has nephritis and hypertension.

Seven of the treated patients gave negative STS and TPI tests. In four, reversal of the STS occurred very rapidly after the institution of treatment. One patient had been treated on serological grounds in 1943, but there was a history suggestive of early syphilis 1 year previously. In another case, the patient had had a congenitally syphilitic child in 1941 which died 4 months after birth. It seems probable that these patients were treated early in latency, and this may account for the negative TPI results.

The number of female patients showing the STSpositive-TPI-negative pattern suggesting non-specificity of the STS greatly exceeded the males showing similar results. This is partly accounted for by the Royal Free Hospital patients who were nearly all females. In the London Hospital patients the sex difference was not significant. An analysis of the patients attending the latter hospital with reference to their racial origin showed that 43 were nonEuropean, mainly West Africans and West Indians. Only one of these, an Indian, showed the pattern suggesting non-specificity of the STS. In some of these coloured patients the positive STS and TPI reactions may well have been due to infection with yaws in childhood, as suggested by Laird (1955), but the TPI test is not of value in differentiating between the treponematoses.

If the finding of a negative TPI test is an acceptable criterion of the non-specificity of the STS reactions, 11.5 per cent. of the untreated patients and possibly 4.4 per cent. of those who had been treated for latent syphilis showed non-specific results with the serum tests using lipoidal antigens. They are of the same order as those reported by Chacko (1953) from St. Mary's Hospital, London, who found that nine out of 101 patients with treated latent syphilis showed negative TPI tests. The results obtained by other workers with sera from patients with latent syphilis and with "prohlem" sera are summarized in Table III.

TABLE III

PROPORTION OF TPI-NEGATIVE SERA REPORTED IN PATIENTS WITH LATENT SYPHILIS AND IN PROBLEM SERA

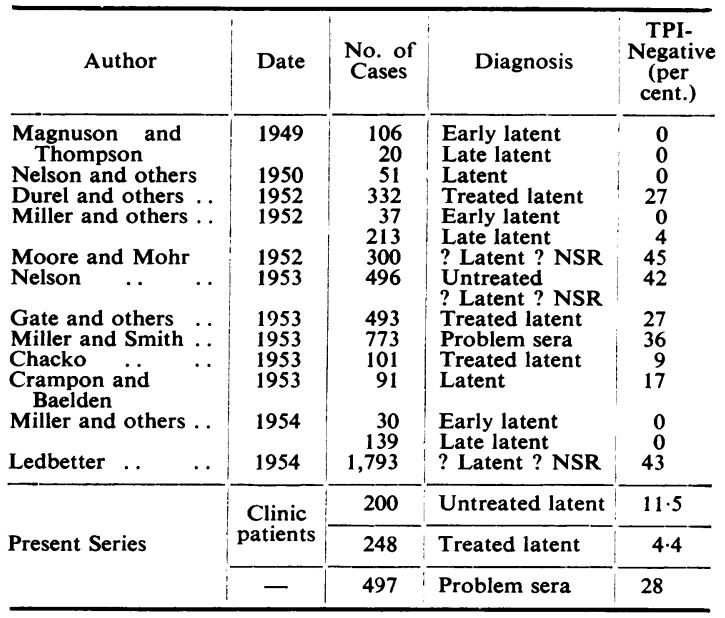


These widely varying figures are probably explained by factors such as the criteria of selection, the varying incidence of syphilis in the populations from whom the patients were drawn, the proportion of treated patients, the possible influence of treatment in early latency, and the types of STS employed.

\section{Results given by the TPI Test in " Problem Sera "}

These sera came from patients who had been found sero-positive at other laboratories on routine testing. Specimens were sent to the V.D. Reference Laboratory either because the original STS had given anomalous results or because the results were at variance with the clinical findings. For descriptive purposes they have been divided into two main classes :

(a) Presumably healthy patients, blood donors (71) and pregnant women (278).

(b) Patients in hospital for a variety of complaints in whom routinely performed STS had been found positive.

It must be emphasized that, because an unknown degree of selection by the physicians may have occurred when sending the sera for a second opinion, the results obtained are not necessarily representative of the types of patients tested. It is probable, for instance, that sera giving weakly positive or discordant STS results would have been sent for checking rather than those giving strongly positive and concordant STS results.

Blood Donors. -94 sera* from 74 patients were examined. In three sera no valid test could be obtained with the TPI, and in two the complementfixation tests were anticomplementary. Excluding these, the comparative STS and TPI results are shown in Table IV.

TABLE IV

RESULTS OF PARALLEL STS AND TPI TESTS ON 69 BLOOD DONORS FOUND SERO-POSITIVE ON ROUTINE SERUM TESTING

\begin{tabular}{c|c|c|c}
\hline STS & \multicolumn{3}{|c}{ TPI } \\
\hline & + & \pm & 0 \\
\hline \pm & 29 & 1 & 9 \\
0 & 11 & - & 15 \\
\hline
\end{tabular}

There was agreement between the STS and the TPI in sera from 45 patients ; in 24 (35 per cent.), however, one or more of the STS were positive, but the TPI was negative, suggesting that the positive STS reactions were non-specific. Analysis of the results by sex showed that this was without

*This figure includes 27 donor sera previously reported (Wilkinson, 1954b). effect. Fourteen of the patients had been treated on the basis of the positive STS findings, but the incidence of STS-positive-TPI-negative results was the same in the treated and untreated groups. This incidence of presumed non-specific reactions is much lower than that reported by Stokes, Boerner, Hitchens, and Nemser (1946). These authors found that $489(0.23$ per cent. $)$ out of 210,261 donors at the Philadelphia Blood Donor Center tested between January and September, 1944, gave definite positive STS reactions. The donors were predominantly white, the series including only 2,579 negroes, and the incidence of sero-positivity was below that reported for the area $(0.5$ per cent.). Extensive clinical and serological investigations were carried out on a sample of 79 patients said to be "essentially unselected" of the 489 sero-positive donors; only 40.5 per cent. were finally adjudged to have syphilis, the remaining 59.5 per cent. being considered to have given non-specific STS reactions.

In most of the patients now reported, the positive STS were found when they volunteered as blood donors, so that they represent positive STS reactions in presumably healthy patients, and any possible effect of repeated donation of blood in the causation of non-specific STS reactions can be excluded.

Pregnancy.-This group included 309 sera* from 279 patients in whom the STS and TPI results could be compared. In 35 patients, the STS had been found positive during pregnancy in the past, and the TPI was carried out at periods varying from 5 months to 8 years after delivery. Thirty-three of the patients had been treated. Comparative results of the two types of test are shown in Table V.

TABLE V

RESULTS OF PARALLEL STS AND TPI TESTS ON 35 PATIENTS FOUND SERO-POSITIVE DURING PREGNANCY IN THE PAST

\begin{tabular}{|c|c|c|c|}
\hline STS & & TPI & \\
\hline & + & $\doteq$ & 0 \\
\hline+ & 16 & - & 5 \\
\hline \pm & 8 & - & 2 \\
\hline 0 & 2 & - & 2 \\
\hline
\end{tabular}

In the remaining 244 patients who had been found sero-positive on routine antenatal testing, the TPI was carried out during pregnancy or the puerperium. Results of the parallel tests are given in Table VI (overleaf).

Altogether 211 of the patients were untreated at the time of testing, 27 had keen treated during the

*Includes 97 pregnancy sera previously reported (Wilkinson, 1954b). 
TABLE VI

RESULTS OF PARALLEL STS AND TPI TESTS ON 244 PATIENTS FOUND SERO-POSITIVE ON ROUTINE TESTING DURING PREGNANCY

\begin{tabular}{c|c|c|c}
\hline STS & \multicolumn{3}{|c}{ TPI } \\
\hline & + & \pm & 0 \\
\hline & 108 & 2 & 21 \\
\pm & 33 & 1 & 46 \\
0 & 3 & 1 & 29 \\
\hline
\end{tabular}

pregnancy, and six had received antisyphilitic treatment in the past, two during a previous pregnancy. There was agreement between the STS and TPI in 173 sera and disagreement in 71. Four patients gave negative STS reactions, while the TPI was positive in three and doubtful in one. Two of these patients had given positive STS reactions on previous specimens, another gave a history of anomalous STS reactions in a previous pregnancy and a fourth had had inadequate treatment for syphilis 9 years previously. In the remaining 67 sera showing disagreement, one or more of the STS were positive while the TPI was negative, suggesting that the positive STS reactions were non-specific in nature. This represents 27.5 per cent. of the total 244 sera in the group. It is usually held that where the STS give concordant results among themselves, the results are more likely to be specific than when the results are discordant. In 131 sera all four STS were positive, and of these 21 , or 16 per cent., were TPI-negative. In marked contrast to this, 46 (57.5 per cent.) of the eighty sera giving discordant STS results were TPI-negative, suggesting that the STS reactions were non-specific. The relationship between the strength of the STS reaction, as judged by the PPR titre, and the outcome of the TPI is shown in Table VII.

TABLE VII

COMPARISON OF THE PPR TITRE AND THE TPI RESULT IN 244 ANTENATAL SERA

\begin{tabular}{|c|c|c|c|c|c|c|c|c|c|}
\hline \multirow[t]{2}{*}{ TPI } & & \multicolumn{8}{|c|}{ PPR Titre } \\
\hline & & 0 & Neat & 2 & 4 & 8 & 16 & 32 & 64 \\
\hline Positive* & $\cdots$ & 22 & 60 & 29 & 13 & 13 & 6 & 5 & 2 \\
\hline Negative. . & $\ldots$ & 65 & 21 & 6 & 1 & 1 & - & 一 & - \\
\hline
\end{tabular}

*Four sera which gave doubtful TPI results have been included in the positive group.

Both treated and untreated patients have been included in this analysis. It is clear that, as the PPR titre rises, the proportion of sera found to be TPInegative falls off sharply, the bulk of the presumed non-specific reactions occurring at titres of 2 and under.
Because of the unknown element of selection in these patients, the figure of $27 \cdot 5$ per cent. presumed non-specific reactions does not necessarily represent the incidence of such reactions to be found in routine antenatal testing. Small series have been reported by Ranque, Gallais, Depieds, andMoignoux (1953) who carried out TPI tests on all antenatal sera found to be STS-positive, and found six out of eighteen to give negative reactions with the TPI test. Wheeler, Van Goor, and Curtis (1954) found 29 out of 39 pregnancy sera which were thought to show acute biological false positive reactions to be TPI-negative. Pigeaud, Sohier, Thivolet, Richard, and Rolland (1954) reported the results of TPI tests on 32 antenatal sera found to be STS-positive on routine testing. The TPI was negative in four out of sixteen patients in whom the STS gave concordant results, and negative in thirteen out of sixteen patients in whom the STS gave discordant results.

In an attempt to estimate the absolute incidence of non-specific reactions in unselected antenatal sera, one of us (P.J.L.S.) has carried out routine TPI tests at the Royal Free Hospital during 1953 and 1954 on all antenatal sera which gave positive STS reactions. Out of 2,512 patients tested, $29(1 \cdot 15$ per cent.) were found to be STS-positive. Ten of these had been referred from the Venereal Diseases Department, and only one of these was TPInegative. The remaining nineteen patients were first found sero-positive on routine antenatal testing, and four of these were TPI-negative. Although the numbers of STS-positive patients are small, they suggest that an appreciable proportion, of the order of one-fifth, of positive reactions first revealed by routine antenatal testing, may be nonspecific. This estimate is in fair agreement with the findings of 27.5 per cent. presumed non-specific reactions in the larger group of pregnancy sera described previously.

Although the absolute incidence of non-specific reactions is probably very low, about 1 in 500 on the above figures, this is of small help to the clinician faced with a patient who has been found seropositive; here, the proportion of positive STS reactions in pregnancy which are non-specific is of much greater importance than the absolute incidence. Even though this is very low, the extensive use of routine antenatal testing must produce, in the aggregate, a very large number of " problem" sera in which the use of the TPI test can be of great help.

There is little or no information about the behaviour of the STS after the end of pregnancy in TPI-negative patients with presumed non-specific STS reactions. In some patients who have been retested after pregnancy they have been negative, 
suggesting that they were of the acute type, but in others they are known to have persisted for several years. In the present series, eight patients were known to have given anomalous STS reactions during a previous pregnancy. In six, one or more of the STS were positive when the patient was again tested during pregnancy, and in one who was STSnegative when the TPI was performed, the STS had been positive on a previous specimen. The TPI was positive in three and doubtful in one patient and negative in four, one of whom had been treated 3 years previously during pregnancy.

Diseases Other than Syphilis.-The preceding groups of blood donors and pregnant women represent presumably healthy persons subjected to routine serum testing. A further 149 patients were suffering from a variety of diseases other than syphilis, and were found to be STS-positive on routine examination, there being no definite clinical evidence suggesting syphilis. The results of parallel STS and TPI tests are shown in Table VIII.

\section{TABLE VIII}

RESULTS OF PARALLEL STS AND TPI TESTS ON 149 PATIENTS WITH DISEASES OTHER THAN SYPHILIS WHO WERE FOUND SERO-POSITIVE ON ROUTINE TESTING

\begin{tabular}{c|c|c|c}
\hline STS & & TPI & \\
\hline & + & \pm & 0 \\
+ & 75 & - & 8 \\
$=$ & 17 & - & 36 \\
0 & 1 & - & 12 \\
\hline
\end{tabular}

Taking the group as a whole, one or more of the STS was positive and the TPI negative in 44 patients (29 per cent.). As in the sera from donors and pregnant women, the majority of the STS-positiveTPI-negative results were found where there was discord among the STS results, 36 (68 per cent.) of the 53 sera of this type being TPI-negative, suggesting that the STS results were non-specific.

The patients were suffering from a wide variety of complaints, but the numbers with any one disease were too small to warrant analysis. Seventeen of the patients had gonorrhoea and were found seropositive on routine testing; the TPI was positive in all but one. Nine patients had non-gonococcal urethritis, and in five of these the TPI was positive.

Some clinical conditions have been recognized to be associated with non-specific STS reactions which persist for long periods. This seems to be well established in lupus erythematosus, leprosy, and the form of haemolytic anaemia due to auto-antibody production. These conditions have therefore been excluded from the preceding group and are presented separately in Table IX.*

Sera from these patients were examined irrespective of whether their STS had previously been found positive. Although the numbers are small, it is

\section{TABLE IX}

RESULTS OF PARALLEL STS AND TPI TESTS IN LUPUS ERYTHEMATOSUS, LEPROSY, AND ACQUIRED HAEMOLYTIC ANAEMIA

\begin{tabular}{|c|c|c|c|c|c|c|c|}
\hline & Disease & & $\begin{array}{l}\text { No. of } \\
\text { Cases }\end{array}$ & STS & \multicolumn{3}{|c|}{ TPI Results } \\
\hline & & & & & + & $=$ & 0 \\
\hline \multicolumn{2}{|c|}{ Lupus Erythematosus } & .. & 20 & $\begin{array}{l}+ \\
\pm \\
\end{array}$ & $\frac{1}{2}$ & $\bar{z}$ & $\begin{array}{l}7 \\
3 \\
9\end{array}$ \\
\hline Leprosy & .. & . & 18 & $\frac{+}{+}$ & $\frac{4}{-}$ & Z & $\begin{array}{l}7 \\
4 \\
3\end{array}$ \\
\hline $\begin{array}{r}\text { Acquired } \\
\text { Anaem }\end{array}$ & Iaemolytic & & 9 & $\frac{+}{\frac{\dot{\bar{t}}}{0}}$ & 二 & 二 & $\begin{array}{l}3 \\
3 \\
3\end{array}$ \\
\hline
\end{tabular}

clear that even sera which gave positive results with all four of the STS were, for the most part, TPInegative while all of the sera giving discordant STS results were negative with the TPI test.

Lupus Erythematosus.-Positive STS were found in eleven of the patients with various types of lupus erythematosus, while the TPI was positive in one.

A female, aged 57, was found to have gummatous ulcers of the uvula and soft palate in 1948. Her STS were strongly positive and the CSF normal. Response to treatment with bismuth and penicillin was satisfactory, the STS titre dropping from 256 to 8 . In 1952 she developed a rash on the face which was diagnosed as chronic discoid lupus erythematosus.

The appearance of non-specific STS reactions does not seem to be directly related to the severity of the lupus erythematosus, as one patient who had completely negative STS had very severe manifestations of generalization of the disease, from which she died shortly afterwards. The positive STS reactions may be present before the signs of lupus erythematosus develop. Haserick and Long (1952) found positive STS reactions in seven out of 29 patients, only one of whom had a history of syphilis. They described five patients in whom periods of up to 7 years elapsed between the finding of positive STS reactions and the development of lupus erythematosus. In the present series, two patients, who were found to have positive STS reactions on routine antenatal testing, were subsequently found to have lupus erythematosus, the diagnosis being confirmed by the finding of L.E. cells. One developed hepatitis and nephritis which

*These include the cases previously reported (Wilkinson, 1954b). 
resulted in the death of the foetus. She was treated with 10 mega units penicillin, but the positive STS have persisted for 4 years. The second patient was known to have been sero-negative during pregnancy in 1949 and had had pneumonia which had been treated with penicillin. In 1951 she again became pregnant and her STS were found to be positive. She showed no clinical evidence of syphilis, but was treated with ten weekly injections of $0.3 \mathrm{~g}$. bismuth followed by 6 mega units penicillin. The child was stillborn. In 1953 she developed arthritis, and on investigation was found to have disseminated lupus erythematosus.

The earlier literature on non-specific STS reactions in this condition has been reviewed by White (1947), who reported three cases, and by Gold and Gowing (1953). Rein and Kostant (1950) found one or more of a battery of six STS positive in 63 out of 178 patients with various types of the disease. They noted that 83 per cent. of the sera were anticomplementary in one or both of the complement-fixation tests used, but found no evidence that the sera giving positive STS reactions specifically showed increased gamma globulins. Zellmann (1952) examined 83 patients with disseminated lupus erythematosus, and found that thirteen gave positive and two doubtful reactions with one or both of two STS used. Only one of these fifteen sero-positive patients had " proved" syphilis, the other fourteen being thought to show possible non-specific reactions.

Leprosy.-This disease has long been thought to be associated with non-specific serum reactions for syphilis. Sera from eighteen lepers were examined ; except for five sera sent from Malta, all were from patients resident in Great Britain. Fifteen were positive with one or more of the STS, but, of these, only four were TPI-positive. One was a West African who also has neurosyphilis, the second was a young Filipino woman who also has pulmonary tuberculosis. Antisyphilitic treatment has been given to the latter, but there has not yet been any significant change in her STS titre. The remaining two sero-positive patients were English; one had skin lesions attributed to leprosy and syphilis by different observers, a biopsy showed no evidence of leprosy. The last patient was a man of 75 who shows no clinical evidence of syphilis.

Earlier work on the occurrence of positive STS in leprosy has been reviewed by Ranque, Tramier, Depieds, and Moignoux (1953). These workers carried out TPI tests on forty leprosy sera (principally from Dakar) and considered fifteen to have given non-specific STS reactions. Nelson (1952) examined sera from seventy patients in the Carville leprosarium ; 57 were STS-positive, of whom only eleven were reactive with the TPI. One of the thirteen STS-negative patients also had a doubtful TPI test. Thivolet, Floch, Rolland, and Sohier (1953) examined sera from eighty lepers, mainly from French Guiana : fifty were positive with one or more STS, but of these, only twelve were TPIpositive, and one of the thirty STS-negative cases was also TPI-positive. Portnoy and Edmundson (1954) in examining 255 leprosy sera found thirty to be reactive with the TPI test, eighteen of these also being reactive with the VDRL slide test. Of the 225 sera which were TPI-negative, 65 were reactive with the VDRL test.

Haemolytic Anaemia.-Although only nine sera were examined from patients with the acquired type of haemolytic anaemia due to auto-antibody production, six of them gave positive reactions with one or more of the STS, while one other had given a bizarre pattern of discordant STS results over the preceding 5 months, but was STS-negative on the specimen on which the TPI was performed. The TPI was negative in all cases. Despite the small number of cases, it seems probable that nonspecific reactions are common in this condition. Presumed false-positive Wassermann and Kahn tests were found in two cases described by Dacie (1954) who refers to earlier work.

Sera were also examined from seven patients with paroxysmal cold haemoglobinuria. In five patients the STS were all positive, usually to a high titre, and these all had a positive TPI test. The remaining two patients were sero-negative with the STS and the TPI. Dacie (1954), in a tentative classification of this condition, differentiates a chronic type associated with syphilis from acute and chronic types of varying aetiology.

\section{Specificity of the STS as judged by the TPI}

In the previous comparative results which have been presented the STS have been considered together as a group, representative of tests for reagin(s) in contrast to the test for immobilizing antibody. If the results of the latter test are taken as a criterion of the specificity of the STS reactions, the performance of the individual STS can be compared. To obviate the influence of antisyphilitic treatment on the tests, treated patients have been excluded and a comparison of results on $\mathbf{5 7 2}$ untreated patients, on whose sera all four STS and the TPI had been carried out on the same specimen, is given in Table $X$ (opposite).

These results show that the order of STS-specificity was PPR $>$ Standard WR (crude heart extract antigen) $>$ Kahn $>$ Cardiolipin WR. The PPR gave 
TABLE $X$

COMPARISON OF THE INDIVIDUAL STS WITH THE TPI ON SERA FROM 572 PATIENTS

\begin{tabular}{|c|c|c|c|c|c|}
\hline Tests & & WR & \begin{tabular}{c|} 
WR \\
Cardio- \\
lipin
\end{tabular} & Kahn & PPR \\
\hline \multirow{2}{*}{ Agreement } & Both Positive & 303 & 340 & 304 & 307 \\
\hline & Both Negative & 144 & 84 & 120 & 156 \\
\hline \multirow{2}{*}{ Disagreement } & STS-0 TPI + & 52 & 15 & 51 & 49 \\
\hline & STS + TPI 0 & $\begin{array}{c}73 \\
\text { (13 per } \\
\text { cent.) }\end{array}$ & $\left|\begin{array}{c}133 \\
\text { (23 per } \\
\text { cent. })\end{array}\right|$ & $\begin{array}{c}97 \\
\text { (17 per } \\
\text { cent.) }\end{array}$ & $\begin{array}{c}60 \\
(10 \text { per } \\
\text { cent. })\end{array}$ \\
\hline
\end{tabular}

less than half the presumed non-specific results which were found with the more sensitive Cardiolipin Wassermann reaction. It should be emphasized that these tests were carried out on a group largely composed of "problem" sera which included a large number of non-specifically reacting sera. It is felt, however, that a comparison of individual STS in a group of this type against the TPI as a standard gives a much truer picture of the specificity of individual STS than the more usual procedure of comparative STS testing on large numbers of routine sera in which the incidence of non-specific reactions is very low. A similar study on 726 problem sera has been reported by MacPherson, Ledbetter, and Martens (1955). They found the Kahn test to give 39.9 per cent. non-specific reactions, the Kolmer 21.4 per cent., and a test using Cardiolipin antigen 29.4 per cent. non-specific reactions.

A comparison of the individual PPR titres against the TPI result in the same group of sera from 572 untreated patients is given in Table XI.

\section{TABLE XI}

COMPARISON OF PPR TITRES AND TPI RESULT ON SERA FROM 572 UNTREATED PATIENTS

\begin{tabular}{l|c|c|c|c}
\hline \multirow{2}{*}{ PPR Titre } & \multirow{2}{*}{ Sera } & TPI & \multicolumn{2}{|c}{ TPI 0 } \\
\cline { 5 - 5 } & & & Number & Per cent.* \\
\hline 0 & 206 & 50 & 156 & \\
Neat & 159 & 132 & 27 & 17 \\
2 & 68 & 53 & 15 & 22 \\
4 & 46 & 41 & 5 & 11 \\
8 & 31 & 25 & 6 & 19 \\
16 & 25 & 20 & 5 & 20 \\
32 & 17 & 16 & 1 & 6 \\
64 and over & 20 & 19 & 1 & 5 \\
\hline
\end{tabular}

*Percentages based on number of sera in each titre group.

This shows that while the bulk of the TPI-negative sera which were reactive with the PPR were of low titre ( 2 dilutions or less), there were small numbers of moderately- or high-titred sera which were considered to be non-specific because of the negative TPI. These results are similar to those of Miller and
Smith (1953) in a similar study using the quantitative Kahn test, and they suggest that, in general, the more strongly positive the reaction given by the STS, the more likely it is to be specific, particularly where the other STS give concordant results. Exceptions to this generalization occur, and some of the highest-titred sera found in the Reference Laboratory have been associated with repeatedly negative TPI tests which have cast doubt on the specificity of the STS concerned. In some cases this has been associated with discordance among the STS results, some tests in the battery giving extremely high titres while others are completely negative, and a prozone can be excluded. A case of this sort has recently been reported by Wilkinson (1954a).

\section{Discussion}

In the evaluation of any serological test it is logical to establish its performance with sera of known antecedents before applying it to the diagnosis of disease. This is even more true of a technique which is designed to validate the results given by other tests. Examination of presumed non-syphilitic sera has shown that the TPI test has a very high specificity. In the small numbers of cases which have been reported where it has given possibly nonspecific reactions, the impossibility of proving the negative contention that the patients concerned had not got syphilis makes it difficult to arrive at a final conclusion, but the figure of 0.3 per cent. possible non-specific reactions given by Zellmann (1954) seems a reasonable estimate.

In this study, the use of the TPI as a verification test has been restricted to latent syphilis. Complete reliance on it in this role presupposes that it will be positive in all cases of untreated latent syphilis. From a consideration of the results in a relatively small number of patients in whom the diagnosis is thought to be well established on other evidence than reactivity of sera with tests using lipoidal antigens, it is clear that the TPI has a very high sensitivity, immobilizing antibody being present in over 99 per cent. of the patients studied. It should be noted, however, that in three cases doubtful reactions were obtained in untreated patients; this suggests the possibility that spontaneous disappearance of the antibody may rarely occur.

Where treatment has been given, it has been assumed as a working hypothesis (Zellmann, 1954) that the behaviour of immobilizing antibody in late latent syphilis (of more than 4 years' duration) is similar to that in late symptomatic syphilis and that it persists indefinitely in almost all cases. While this assumption is reasonable, it is often very difficult to 
assign an infection to " early" or "late" latency, and this uncertainty will affect the interpretation of a negative TPI test in such cases.

The titre of immobilizing antibody is usually high in latency, and reactions in the "doubtful" range are only rarely found ; of the 1,126 sera examined in the present study only ten, or 0.9 per cent., gave doubtful reactions.

It is considered that the TPI test fulfils the criteria of specificity, high sensitivity, and ability to give clear-cut results which were suggested as essentials for a verification test to be used in suspected latent syphilis. A positive reaction is considered to be good evidence of past treponemal infection, but it must be stressed that this is not necessarily an indication of present activity of the disease. In untreated patients in whom the only suggestion of syphilis comes from positive STS results, the finding of a negative TPI test, which is confirmed by repetition on a second specimen of serum after an interval of at least a month, is very strong evidence that the STS reactions are non-specific in nature. A confirmed negative TPI result in patients who have been treated for supposed latent syphilis on positive STS findings alone suggests nonspecificity of the latter tests, but, until more direct evidence of the behaviour of immobilizing antibody in patients treated in known early latency is available, it is felt that judgment should be reserved.

Application of the TPI test to sera from blood donors and pregnant women found STS-positive on toutine testing has suggested that a significant proportion of these positive reactions are nonspecific. The observed incidences of 35 per cent. and 27.5 per cent. presumed non-specific reactions in donor and antenatal sera are probably overestimates because of the selected nature of the sera. Experience with unselected antenatal sera at the Royal Free Hospital suggests that the figure is of the order of 20 per cent. While even this latter figure seems disconcertingly large, reflecting discredit on the STS employed, it is important to view it in perspective and to realize that it also means an incidence of only 0.2 per cent. nonspecific reactions among the total 2,512 sera tested, which is acceptable for a serum test. Knowledge of the proportion of positive STS in pregnancy which may be non-specific is, however, of more immediate value to the clinician faced with a pregnant woman whose routine tests have been found to be positive. Examination of untreated patients with suspected latent syphilis attending venereal disease clinics has shown that in about one in ten the TPI is negative, suggesting that the STS are non-specific, and that, of those treated in the past, 4.4 per cent. are TPI- negative. It is felt that these proportions are sufficiently large to emphasize the need for some form of confirmatory test to establish the validity of the STS in these types of patients. At present, the TPI, despite its technical difficulty, seems to offer the best approach to the problem. Two other verification tests used in recent years, the Kahn verification test and the Neurath euglobulin inhibition test, were compared with the TPI on a small series of sera, but were not thought to give reliable results (Harrell, 1953 ; Roy, Hill, Gowdey, Kelces, and Rein, 1953).

While the immobilization test is of great help in the investigation of patients thought to give nonspecific STS reactions, it does not answer the fundamental question why some patients, either in apparent good health or suffering from diseases other than syphilis, should give non-specific reactions with serum tests for syphilis. Kahn (1950), in his work on the Universal Serological Reaction, suggests that as a result of normal tissue wear and tear, lipoidal substances are produced which give rise to auto-antibodies which react with the lipoids in these antigens. These "normal" antibodies may sometimes be strong enough to overflow into the diagnostic zone of the Kahn test and give a positive result. Under appropriate test conditions, different serological patterns are produced, and it is thought that not only established non-specific reactors can be recognized, but also normal individuals who are potential non-specific reactors, their precipitation patterns closely approaching the diagnostic zone of the universal reaction, but not encroaching upon it. This hypothesis is attractive in its simplicity, but as yet no data have been published on the results given by the TPI test on sera which have shown the non-specific pattern of reaction when examined by Kahn's new technique.

An alternative possibility is raised by the work of Lindau and Laurell (1952). These authors subjected normal, Wassermann Reaction-negative sera to paper electrophoresis, and separated protein fractions of varying mobilities by elution of sections of the filter paper. They found that the faster part of the $\gamma$-globulin fraction gave positive Wassermann and Kahn reactions which were reversed by Neurath's inhibitor. They suggest that normal sera contain reagins whose effects are neutralized by an inhibitory substance normally present, and that non-specific STS reactions might be due to an imbalance with a decrease in the inhibitor.

The possibly serious prognostic implication of presumed non-specific STS reactions has been suggested by the work of Moore and others (Moore and Mohr, 1952a, b ; Moore and Lutz, 1955). A 
group of patients from a private practice who showed no evidence of syphilis, other than repeatedly positive STS, was kept under observation for long periods. On the basis of negative TPI tests, the STS, most of which had been discovered on routine testing, were considered to be non-specific. Detailed clinical examinations and laboratory investigations showed that a considerable proportion of these patients had evidence of unsuspected collagen disorders or that the tests showed abnormalities reflecting alterations in the $\gamma$-globulins. In the most recent survey (Moore and Lutz, 1955) it was found that out of 148 patients examined, ten had proved systemic lupus erythematosus, while 45 had "probable" collagen vascular disease (usually systemic lupus erythematosus).

While this work underlines the need to investigate patients with presumed non-specific reactions, and not simply to dismiss them when the diagnosis of syphilis is thought to be excluded, there are some features which need stressing. By no means all patients with systemic lupus erythematosus show nonspecific STS reactions, and these may be absent even when the systemic manifestations are very severe. Lupus erythematosus is an ill-defined condition and protean in its manifestations (as emphasized in the recent review by Haserick, 1955), and Moore and Lutz only regard the diagnosis as "proved" in a minority of the patients they have studied, but further observation of the patients placed at present in the "probable" category may result in the establishment of a definite diagnosis. Moore's patients are drawn from a narrow population group, and further work is needed to show whether his results are applicable to other classes of patients showing the chronic type of non-specific reaction, when it is not associated with any obvious precipitating cause.

\section{Summary}

(1) Immobilizing antibody has been demonstrated in all save one of 136 patients in whom the diagnosis of latent syphilis was corroborated by other evidence than the STS results alone. In view of the specificity of the test, its great sensitivity, and its ability to give clear-cut results, it is thought to be eminently suitable as a verification test in patients with suspected latent syphilis. In an untreated patient where the only presumptive evidence of syphilis rests on positive STS results, it is considered that a negative TPI test, confirmed on a second specimen of serum, is good evidence that the STS results are non-specific in nature.

(2) The TPI was found to be negative in 11.5 per cent. of 200 untreated patients coming to venereal disease clinics with suspected latent syphilis, and in 4.4 per cent. of 248 such patients who had been diagnosed and treated for latent syphilis in the past.

(3) 35 per cent. of problem sera from blood donors, and 27.5 per cent. of problem antenatal sera from patients found to be STS-positive on routine testing gave negative TPI tests. In an unselected group of antenatal sera about one-fifth of those giving positive STS were TPI-negative. Out of 149 patients with diseases other than syphilis who had been found STS-positive on routine testing, 29 per cent. gave negative TPI tests.

(4) Using the TPI as a criterion of specificity, an analysis is presented of the performance of four representative STS using lipoidal antigens.

(5) Recent concepts of the nature and possible significance of non-specific STS reactions are briefly discussed.

Our thanks are due to the Directors of the Clinics at the London and Royal Free Hospitals for access to clinical records and to the many clinicians who have sent us sera for testing, and to Dr. I. N. Orpwood Price for his encouragement and criticisms. We are also indebted to Dr. B. Boxall and to our technicians, Mr. A. D. Lucas and Mrs. A. Chasse, for their assistance in the routine execution of the test.

\section{REFERENCES}

Chacko, C. W. (1953). J. clin. Path., 6, 227.

Crampon, P., and Baelden, J. (1953). Ann. Inst. Pasteur Lille, 5, 191.

Dacie, J. V. (1954). "The Haemolytic Anaemias". Churchill, London.

D'Alessandro, G., Oddo, F. G., and Dardanoni, L. (1950). J. vener. Dis. Inform., 31, 314.

Durel, P., Sausse, A., and Borel, L-J. (1952). British Journal of Venereal Diseases, 28, 68.

Edmundson, W. F., Olansky, S., Wood, C. E., and Kamp, M. (1955). Arch. Derm. Syph. (Chicago), 71, 387.

Gaté, J., Sohier, R., and Thivolet, J. (1953). In “ Le T.P.I.-Test de Nelson-Mayer et les nouveaux aspects immunologiques de la Syphilis". Société française de Dermatologie et Syphiligraphie. Colloque $\left(3^{\mathrm{e}}\right)$ de la filiale marseillaise. Marseille, October, 1953. Masson, Paris.

Gold, S. C., and Gowing, N. F. C. (1953). Quart. J. Med., 22, 457

Hardy, P. H., and Nell, E. (1955). J. exp. Med., 101, 367.

Harrell, E. R. (1953). Amer. J. Syph., 37, 330.

Haserick, J. R. (1955), J. chron. Dis., 1, 317.

- and Long, R. (1952). Ann. intern. Med., 37, 559.

Kahn, R. L. (1950). "Serology with Lipid Antigen". Baillière, Tindall and Cox, London.

and McDermott, E. B. (1953). Univ. Mich. med. Bull., 19, 163.

Laird, S. M. (1955). British Journal of Venereal Diseases, 31, 30.

Ledbetter, R. K. (1954). Amer. J. Syph., 38, 522.

Lindau, A., and Laurell, A. B. (1952). Acta Path microbiol. scand., Suppl. 93, 378.

MacPherson, D. J., Ledbetter, R. K., and Martens, V. E. (1955). Amer. $J$ clin Path, 25, 89.

Magnuson, H. J., and Thompson, F. A. (1949). J. vener. Dis. Inform., 30, 309.

Miller, G. W., and Smith, H. B. (1953). Amer. J. Syph., 37, 424.

Miller, J. L., Slatkin, M. H., Feiner, R. R., Portnoy, J., and Cannon, A. B. (1952). J. Amer. med. Ass., 149, 987. , Brodey, M., Wechsler, H. L., and Hill, J. H. (1954). Ibid., 154, 1241.

Moore, J. E., and Lutz, W. B. (1955). J. chron. Dis., 1, 297. 
Moore, J. E., and Mohr, C. F. (1952a). J. Amer. med. Ass., 150, 467. (1952b). Ann. intern. Med., 37, 1156.

Nelson, R. A., and Mayer, M. M. (1949). J. exp. Med., 89, 369.

Zheutlin, H. E. C., Diesendruck, J. A., and Austin, P. G. M (1950). Amer. J. Syph., 34, 101.

(1952). British Journal of Venereal Diseases, 28, 160.

(1953). Amer. J. Syph., 37, 1.

Pigeaud, H., Sohier, R., Thivolet, J., Richard, G., and Rolland, M. (1954). Ann. Méd., 55, 393.

Portnoy, J., and Edmundson, W. F. (1954). Int. J. Leprosy, 22, 181. Price, I. N. O. (1948). J. clin. Path., 1, 91.

(1950). British Journal of Venereal Diseases, 26, 172.

Ranque, J., Gallais, P., Depieds, R., and Moignoux, J. B. (1953). "Le T.P.I.-Test de Nelson-Mayer et les nouveaux aspects immunologiques de la Syphilis". Masson, Paris.

-, Tramier, G., Depieds, R., and Moignoux, J. B. (1953). Ibid.

Rein, C. R., and Kostant, G. H. (1950). Arch. Derm. Syph. (Chicago), $61,898$.
Roy, A. N., Hill, J. H., Gowdey, J. L., Kelcec, L. C., and Rein, C. R. (1953). Amer. J. Syph., 37, 338.

Sequeira, P. J. L., and Wilkinson, A. E. (1955). British Journal of Venereal Diseases, 31, 134.

Stokes, J. H., Boerner, F., Hitchens, A. P., and Nemser, S. (1946). J. Amer. med. Ass., $130,57$.

Tani, T., and Asano, O. (1951). Jap. med. J., 4, 51.

Thivolet, J., Floch, H., Rolland, M., and Sohier, R. (1953). In "Le T.P.I.-Test de Nelson-Mayer et les nouveaux aspects immunologiques de la Syphilis". Masson, Paris.

Wheeler, A. H., Van Goor, K., and Curtis, A. C. (1954). Amer. J. Syph., 38, 437.

White, C. J. (1947). Ibid., 31, 235.

Wilkinson, A. E. (1954a). British Journal of Venereal Diseases, 30, 38.

(1954b). Ibid., 30, 144

Zellmann, H. E. (1952). Amer. J. Syph., 36, 163.

(1954). Ibid., 38, 506. 